\title{
Urinary catecholamine concentrations in three beef breeds at slaughter
}

\author{
H.A. O’Neill ${ }^{\text {\#\# }}$, E.C. Webb ${ }^{1}$, L. Frylinck ${ }^{2}$ \& P. Strydom ${ }^{2}$ \\ ${ }^{1}$ Department of Animal and Wildlife Science, University of Pretoria, Pretoria 0002, South Africa \\ ${ }^{2}$ Intensive Red Meat Production Unit, Agricultural Research Council - Animal Production Institute, Private Bag \\ x2, Irene 0062, South Africa
}

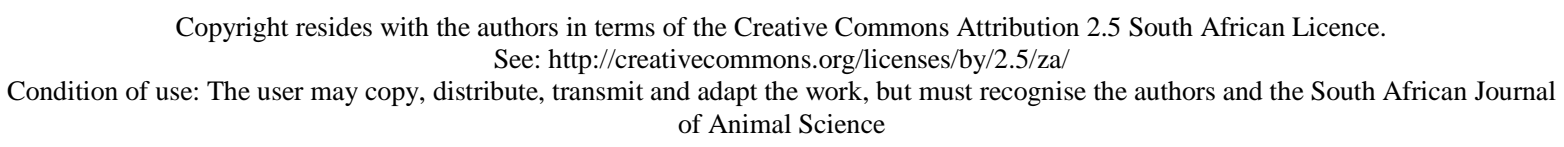

\begin{abstract}
Animal welfare has become an important determinant of meat quality with poor animal temperament leading to huge economic losses to the meat industry due to carcass bruising and condemnation. Handling and transport of live animals is a stressful experience for animals. The temperaments of cattle affect their behaviour and differ between breeds, i.e. studies have shown that Bos indicus types are more temperamental than Sanga and Bos taurus types. Catecholamines (CAT's) are considered as indicators of stress, because higher concentrations of CAT's in brain tissue were noted in animals that are better adapted to stressful situations. In the present study, urinary CAT's of three beef breeds were determined immediately post mortem. Brahman cattle represented Bos indicus types, Simmentaler cattle represented Bos taurus types and Nguni cattle represented the Sanga type. Nguni steers showed higher urinary norepinephrine (NE) and epinephrine (E) concentrations than Brahman and Simmentaler steers. Simmentaler steers showed a higher concentration of urinary dopamine (DA) than $\mathrm{Br}$ and $\mathrm{Ng}$. The results suggest that Nguni cattle are less stress sensitive compared to the other beef breeds studied. These observations may be due to the process of domestication and selection for specific genes that influence tameability and consequently resulting in a shift in circulating concentrations of urinary CAT's.
\end{abstract}

Keywords: Animal welfare, breed divergence, animal temperament, stress

\#Corresponding author: adri.oneill@up.ac.za

\section{Introduction}

Stress experienced by slaughter stock is unavoidable and animal welfare issues have become an important determinant of meat quality as perceived by the consumer. Transport, handling and mixing of animals from unfamiliar groups lead to stress (Ferguson \& Warner, 2008).

The fear response of cattle towards human handling is defined as their temperament (Fordyce et al., 1985; Petherick et al., 2003). After transportation, cattle with higher temperament scores have more bruises along the back and around tuber coxae and tuber ischii areas leaving them with lower carcass grading scores (Fordyce et al., 1988b). Any bruised tissue trimmed from a carcass reduces carcass weight and, in turn, decreases the economic return to the producer and yield to the processor. Removal of bruised tissue is time consuming and adds to labour costs. Rails become congested and moving production lines halted and thereby interrupting or reducing the throughput and efficiency of the plant (McNally \& Warriss, 1996).

Animals that display less fearful behaviour during routine handling and management are less likely to injure themselves and their handlers. The heritability of animal temperament is relatively high $\left(\mathrm{h}^{2}=0.45\right)$ (Lanier et al., 2000); therefore, selection for improved temperament or less fearful cattle, can facilitate both human (i.e. handler) and animal welfare (Ferguson \& Warner, 2008).

The evolutionary relationship between the two main types of cattle, the humped zebu (Bos indicus) and humpless taurine (Bos taurus), have been an active area of research to explain genetic differences between the two subspecies. Phylogenetic analyses and data from other disciplines provide the strongest evidence to date for independent domestications of zebu and taurine cattle. Although controversial, it seems 
as if the Bos taurus subspecies has a longer domestication time line compared to Bos indicus (Loftus et al., 1994). Cattle with more Brahman breeding, notably of the Bos indicus subtypes, have higher temperament scores compared to those with lower or no Brahman influence (Voisinet et al., 1997). However, the main characteristic of Bos indicus cattle that distinguishes them from Bos taurus cattle is their high degree of adaptability to hot climates. The Nguni cattle breed can be classified as an ecotype of a group of cattle breeds known as Sanga cattle - Bos taurus africanus. These cattle may have evolved from crosses between Zebu (indicine) and humpless Hamitic longhorn and shorthorn cattle (taurine) in central and east Africa around 1600 BC (Payne, 1964).

Catecholamines (CAT's) are the neurotransmitters and hormones of the adrenomedullary, sympathoneuronal and brain catecholaminergic systems discovered at the beginning of the 20th century (Kvetnansky et al., 2009). The discovery was based on experiments by Walter Cannon (1929) who described the importance of adrenal medullary secretions of "adrenaline" during various types of stimulation in animals and humans. The terms homeostasis and "fight-or-flight" were introduced to the scientific literature and are still being used today (Kvetnansky et al., 2009).

In research on the domestication of wild rats, lower levels of whole brain norepinephrine (NE) were found in wild rats compared to domesticated rats (Cuomo-Benzo et al., 1977). The researchers concluded that selection pressures have favoured a higher whole brain NE content in the domesticated rat, thus enabling it to perform effectively in laboratory test situations. Thus, domestication has resulted in significant increments in whole brain NE and epinephrine (E) content in rats (Cuomo-Benzo et al., 1977). Two possible mechanisms were hypothesized. Significant increments in NE and E content in whole brain of domesticated rats could either be the result of an increase in the biosynthetic enzymes or a decrease in the degrading enzymes. Similarly, classic research regarding tameness and domestication of silver foxes shows that tameness in the presence of humans can be directly related to brain chemistry (Price, 1999). Selection for tameness in foxes and rats influences the catecholamenergic system of the brain (Cuomo-Benzo et al., 1977; Price, 1999). The aim of this study was to compare post mortem urinary CAT concentrations of three beef cattle breeds used in South Africa.

\section{Materials and Methods}

This project was approved by the Ethics Committee of the Agricultural Research Council (ARC). Steers from three beef breeds, Brahman $(n=60)$, Simmentaler $(n=60)$ and Nguni $(n=60)$ were purchased from a commercial farmer. All animals were treated in the same way during the growth and feeding period and fed the same feed. Initially the animals were kept on pastures at the ARC-AII research farm at Groblersdal, followed by fattening at the ARC-ANPI feedlot. Normal processing procedures were carried out on the animals (weighing and vaccination). The animals received implants (Revalor-S) as applied under normal South African feedlot conditions. All steers were housed in small pens holding 10 animals each with each animal having $10 \mathrm{~m}^{2}$ area and $50 \mathrm{~cm}$ of feed-bunk space. Clean, fresh water was available ad libitum. After a 21 day adaptation period during which hay intake was decreased from $15 \%$ to $6 \%$, all steers were fed a standard high concentrate diet (12 MJ/kg DM, $13.5 \mathrm{~g} \mathrm{CP} / \mathrm{kg})$. Slaughtering and sampling took place at the Meat Science Centre of ARC-ANPI research abattoir. The animals were slaughtered at the specified A-age and fatness-class 2-3. In order to measure urinary CAT's, NE, E and dopamine (DA), urine was collected from the bladders with a syringe and needle, immediately after evisceration (approximately 12 minutes post mortem). Four millilitres of urine was mixed with $50 \mathrm{~mL}$ of concentrated $\mathrm{HCl}$ to stabilise and preserve urinary CAT's. After $\mathrm{HCl}$ was added, all samples were transported on ice to the laboratory and then stored at $-70{ }^{\circ} \mathrm{C}$ until analysis. At the time of analysis, the urine samples were sent to a local pathology laboratory (Ampath). Catecholamines were extracted from the urine samples by cation-exchange solid phase extraction and determined by using a high performance liquid chromatography method, as described by Gouarne et al. (2004) and briefly explained by Muchenje (2007). Concentrations of CAT's are volume related and therefore creatinine adjusted concentrations were used in the statistical analysis. Data was analysed by multifactorial analysis of variance by means of the GLM procedure of SAS (2008) at a significance level of $P<0.05$. Comparisons between breeds were evaluated by means of Bonferroni's Multiple Range Test. 


\section{Results and Discussion}

Urinary $\mathrm{NE}, \mathrm{E}$ and $\mathrm{DA}$ concentrations for $\mathrm{Br}, \mathrm{Ng}$ and $\mathrm{Sm}$ cattle are presented in Table 1. Higher urinary catecholamine concentrations could indicate that an animal from a specific breed is more adaptable to interactions with humans and less fearful of animals, resulting in fewer carcasses getting bruised during transport and handling which will lead to higher meat quality. In comparison with the Brahman and Simmentaler, the highest $(P<0.05)$ concentrations of urinary NE and E were measured for Nguni steers. Simmentaler steers had the highest concentrations of urinary DA $(P<0.05)$ in comparison with Brahman and Nguni. From classic domestication studies with silver foxes and rats, animals with a possible longer history of domestication had higher CAT levels in the central and peripheral nervous system (Nikulina, 1990; Price, 1999) as was the case for the Nguni in this study. Simmentaler cattle, which is representative of the Bos taurus subspecies, was possibly domesticated at an earlier time line than Bos indicus cattle (Loftus et al., 1994) and also had higher concentrations of total urinary CAT’s.

Table 1 Least Square Means $( \pm$ SE) for urinary norepinephrine, epinephrine and dopamine concentrations

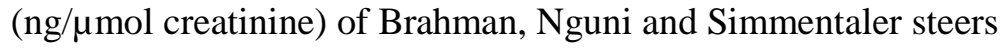

\begin{tabular}{|c|c|c|c|}
\hline \multirow{2}{*}{ Catecholamines } & \multicolumn{3}{|c|}{ Beef breeds } \\
\hline & Brahman & Nguni & Simmentaler \\
\hline Norepinephrine $^{\dagger}$ & $3.23^{a} \pm 0.28$ & $4.12^{b} \pm 0.28$ & $2.98^{\mathrm{a}} \pm 0.28$ \\
\hline Epinephrine $^{\dagger}$ & $1.87^{\mathrm{a}} \pm 0.25$ & $2.81^{b} \pm 0.26$ & $1.71^{\mathrm{a}} \pm 0.25$ \\
\hline Dopamine $^{\dagger}$ & $4.32^{\mathrm{a}} \pm 0.66$ & $5.55^{a} \pm 0.67$ & $7.55^{b} \pm 0.66$ \\
\hline Total & 8.421 & 12.48 & 12.24 \\
\hline
\end{tabular}

Past research and the results of the present study suggest that the concentrations of CATs increased during the domestication of animals. Price (1999) described tameness towards humans and associated ease of handling as among the most important aspects of the domesticated phenotype. The historical development of Nguni cattle occurred in close association with the people of a tribe and in a kraal with other animals. This as well as its selection as a draught animal has resulted in a very docile breed with exceptionally good temperament (Bester et al., 2005). Nguni cattle (Bos africanus / Sanga) developed by natural selection in a highly challenging environment. Brahman cattle have achieved acceptance for their environmental adaptability, longevity, mothering ability and efficient beef production, but has a bad reputation due to poor temperament. The Simmentaler is an influential breed whose history dates back to the Middle Ages. Early records indicate that the Simmentaler originated as a result of crosses between large German cattle and a smaller breed indigenous to Switzerland (Voisinet et al., 1997a).

Catecholamines are not only involved in the domestication time line of an animal, but also in hyperactivity. Numerous animal studies showed the importance of NE in attention-related behaviours which involve search and exploratory activity, distractibility, response rate, discriminability and switching of attention (Anisman \& Zacharko, 1986 from: Schaeffer et al., 2001). When CAT synthesis is compromised, animals become less resistant to stress, developing an array of counterproductive behavioural (learned helplessness) and physiological changes. Such animals are unable to respond appropriately to stimuli and are unable to function normally, to the extent that even eating and sleeping are disturbed.

In humans, attention deficit hyperactivity disorder (ADHD) is a hyperkinetic disorder clinically characterized by inattentiveness, impulsivity and hyperactivity (Kopeckova et al., 2006). According to Haller et al. (1998), either an imbalance in $\mathrm{E}$ synthesis or $\alpha 2$-adrenoceptor number (or affinity) led to the development of ADHD and agents that increased brain NE, improved attention in rats. Kopeckova et al. (2006) explained that a dysfunction or imbalance between the dopaminergic and noradrenergic systems and alterations of DA / NE levels can result in hyperactivity. 
Norepinephrine mechanisms are also involved in pain perception (Haller et al., 1998) and therefore it seems that the main role of NE release subsequent to the onset of a socially relevant stimulus is the establishment of both somatic and neural conditions that ensures maximal efficiency in coping during stressful situations (Haller et al., 1998).

Both animal temperament (Lanier et al., 2000) and ADHD (Sontag et al., 2010) are medium to highly heritable. The enzyme responsible for the conversion of DA into NE is known as DBH, as was described earlier. The DBH protein is released in response to stimulation. DBH activity is derived mainly from sympathetic nerves and can be measured in human plasma. Galvin et al. $(1995,1997)$ measured decreased activities of DBH in serum and urine in patients with ADHD. Also, low DBH levels correlate indirectly with the seriousness of the hyperkinetic syndrome in children (Galvin et al., 1995; 1997). Polymorphisms occur frequently in the DBH gene, the G444A, G910T, C1603T, C1912T, C-1021T, 5'-ins/del and TaqI. These polymorphisms may affect the function of gene products or modify gene expression and thus influence the progression of ADHD (Kopeckova et al., 2006).

\section{Conclusion}

This study indicated that the urinary CAT's of three beef breeds that were determined immediately post mortem, differed. The tameness towards humans and associated ease of handling of Nguni cattle corresponds with its higher levels of urinary norepinephrine and epinephrine. Simmentaler steers had the highest concentrations of total urinary CAT's whereas Brahman steers had the lowest levels of CAT's. Concentrations of urinary CAT's differ between breeds and explain differences in stress responsiveness, temperament and susceptibility to carcass bruising. As genetic polymorphisms of genes have been described for the expression of, for example $\mathrm{DBH}$, it seems as if the Nguni went through a long natural selection process for docility. It seems as if the Simmentaler (being Bos taurus with an earlier domestication) has a genetic disposition to produce more DBH. Based on the differences in the concentrations of urinary CAT's, it seems possible to identify genetic markers for the selection for better temperament and docility in beef cattle. Brahman cattle in particular have been described as a temperamental breed. Selection for the DBH gene may decrease the occurrence of bruised carcasses and improve meat quality. Increased tameness towards humans and handling may also be of importance from an animal welfare perspective.

\section{References}

Arnsten, A.F., Steere, J.C. \& Hunt, R.D., 1996. The contribution of alpha 2-noradrenergic mechanisms of prefrontal cortical cognitive function. Potential significance for attention-deficit hyperactivity disorder. Arch. Gen. Psychiat. 53, 448-455.

Bester, J., Matjuda, L.E., Rust, J.M. \& Fourie, H.J., 2003. The Nguni: A Case Study. Community-based management of animal genetic resources, Agricultural Research Council, Pretoria.

Cuomo-benzo, M., Price, E.O. \& Hartenstein, R., 1977. Catecholamine levels in whole brain of stressed and control domestic and wild tats (Rattus norvegicus). Behav. Process. 2, 33-40.

Ferguson, D.M. \& Warner, R.D., 2008. Have we underestimated the impact of pre-slaughter stress on meat quality in ruminants? Meat Sci. 80, 12-19.

Fordyce, G., Goddard, M.E., Tyler, R. Williams, G. \& Toleman, M.A., 1985. Temperament and bruising of Bos Indicus cross cattle. Aust. J. Exp. Agric. 25, 283-288.

Fordyce, G., Wythes, J.R. Shorthose, W.R., Underwood, D.W. \& Shepherd, R.K., 1988. Cattle temperament in extensive beef herds in Northern Queensland. 2. Effect of temperament on carcass and meat. Aust. J. Exp. Agric. 28, 689-693.

Galvin, M., TenEyck, R., Shekhar, A., Stilwell, B., Fineberg, N., Laite, G. \& Karwisch, G., 1995. Serum dopamine- $\beta$-hydroxylase and maltreatment in psychiatrically hospitalized boys. Child Abuse Neglect. 19, 821-832.

Galvin, M., Stilwell, B.M., Shekhar, R., Kopta, S.M. \& Goldfarb, S.M., 1997. Maltreatment, conscience fuctioning and dopamine- $\beta$-hydroxylase in emotionally disturbed boys. Child Abuse Neglect. 21, 83-92.

Gouarne, C., Foury, A. \& Duclos, M., 2004. Critical study of common conditions of storage glucorticoids and catecholamines in 24-h urine collected during resting and exercising conditions. Clin. Chim. Acta. 348, 207 -214. 
Haller, J., Makara, G.B. \& Kruk, M.R., 1998. Catecholamenirgic involvement in the control of aggression: Hormones, the peripheral sympathetic and central noradrenergic systems. Neurosci.Biobehav. R. 22, 85-97.

Kopeckova, M., Palct, I. \& Goetz, P., 2006. Polymorphisms of Dopamine- $\beta$-Hydroxylase in ADHD children. Folia Biol.-Prague. 52, 194-201.

Kvetnansky, R., Sabban, E.L. \& Palkovits, M., 2009. Catecholamenirgic systems in stress: Structural and molecular genetic approaches. Physiol. Rev. 89, 535-606.

Lanier, J.L., Grandin, T., Green, R.D., Avery, D. \& McGee, K., 2000. The relationship between reaction to sudden, intermittent movement and sounds and temperament. J. Anim. Sci. 78, 1467-1474.

Loftus, R.T., Machugh, D.E., Bradley, D.G., Sharp, P.M. \& Cunningham, P., 994. Evidence for two independent domestications of cattle. Proc. Nadl. Acad. Sci. USA. 91, 2757-2761.

McNally, P.W. \& Warriss, P.D., 1996. Recent bruising in cattle at abattoirs. Vet. Rec. 138, 126-128.

Mefford, I.N. \& Potter, W.Z., 1989. A neuroanatomical and biochemical basis for attention deficit disorder with hyperactivity in children: a defect in tonic adrenaline mediated inhibition of locus coeruleus stimulation. Med. Hypotheses 29, 33-42.

Muchenje, V., 2007. Growth performance, carcass characteristics and meat quality of Nguni, Bonsmara and Angus steers raised on natural pasture. PhD thesis. Department of livestock and Pasture Science, University of Fort Hare, South Africa.

Pliszka, S.R., McCracken, J.T. \& Maas, J.W., 1996. Catecholamines in attention-deficit hyperactivity disorder: current perspectives. J. Am. Acad. Child Adolesc. Psychiatry 35, 264-272.

Payne, W.J.A., 1964. The origin of domestic cattle in Africa. Empire Journ. of Exper. Agric. 32, 97-113.

Petherick, J.C., Holroyd, R.G. \& Swain, A.J., 2003. Performance of lot-fed Bos indicus steers exposed to aspects of a feedlot environment before lot-feeding. Aust. J. Exp. Agric. 43, 1181-1191.

Price, E.O., 1999. Behavioral development in animals undergoing domestication. Appl. Anim. Behav. Sci. 65, 245-271.

SAS, 2008. Statistical Analysis System user's guide ( $2^{\text {nd }}$ ed.) (Version 9.2). SAS Institute Inc., Cary, North Carolina, USA.

Schaeffer, A.L., Dubeski, P.L., Aalhus, J.L. \& Tong, A.K.W., 2001. Role of nutrition in reducing antemortem stress and meat quality aberrations. J. Anim. Sci. 79, 91-101.

Sontag, T.A., Tucha, O., Walitza, S. \& Lange, K.W., 2010. Animal models of attention deficit/hyperactivity disorder (ADHD): a critical review. Atten. Defic. Hyperact. Disord. 2, 1-20.

Voisinet, B.D., Grandin, T., O’Connor, S.F., Tatum, J.D. \& Deesing, M.J., 1997. Bos indicus-cross feedlot cattle with excitable temperaments have tougher meat and a higher incidence of borderline dark cutters. Meat Sci. 46, 367-370. 